\title{
O estágio no processo da formação profissional em Serviço Social: dimensão socioeducativa e os desafios à contracorrente
}

\author{
Maria Célia Correia Nicolau \\ Universidade Federal do Rio Grande do Norte (UFRN)
}

\author{
Tássia Rejane Monte Santos \\ Universidade Federal do Rio Grande do Norte (UFRN)
}

\begin{abstract}
O estágio no processo da formação profissional em Serviço Social: dimensão socioeducativa e os desafios à contracorrente

Resumo: O objetivo do artigo é expor algumas reflexões sobre os desafios históricos e contemporâneos relativos ao processo de estágio, parte integrante da formação profissional na área de Serviço Social. Apresenta uma análise teórico-crítica que ressalta, no projeto de formação em de Serviço Social, reflexos da cultura profissional crítico-hegemônica, estabelecendo uma relação direta entre a postulação da nova tradição profissional e os limites postos a sua materialização. Conclui que o exercício profissional integra o processo de aprendizagem em um movimento contínuo de reconfiguração e reconstrução do saber, incorporando o novo entre formandos e formadores. Palavras-chave: Estágio. Formação profissional. Serviço Social. Dimensão socioeducativa.
\end{abstract}

Internships in Professional Education in Social Work: the socio-educational dimension and challenges to the counter-current

Abstract: This article reflects on the historic and contemporary challenges related to the internship process, an integral part of professional education in the field of social work. It presents a theoretical-critical analysis that emphasizes, in education in social service, reflections on the hegemonic-critical professional culture, establishing a direct relationship between the proposal for a new professional tradition and the limits presented to its materialization. It concludes that the professional practice is part of the learning process in a continuous movement of reconfiguration and reconstruction of knowledge, incorporating the new among students and teachers.

Keywords: Internships. Professional education. Social Service. Socio-educational dimension. 


\section{Situando a problemática}

Pensar o estágio no processo da formação profissional do assistente social e sua dimensão socioeducativa supõe, em primeiro lugar, entendê-lo na lógica das diretrizes curriculares, síntese da proposta do novo projeto de formação profissional em Serviço Social, construído e reconstruído nas décadas de 1980/90, no Brasil, o qual integra o projeto ético-político da profissão. Em segundo lugar, podemos dizer que exige considerar as mudanças conjunturais e estruturais que se abateram sobre a formação profissional, especialmente, no contexto dessa última década. Tais mudanças só podem ser apreendidas se forem situadas no contexto histórico das contrarreformas capitalistas recentes, particularmente, no que diz respeito à implementação da programática neoliberal em nosso país. Por último, há também que considerar os impactos sobre o mercado de trabalho e sobre a vida social, bem como suas refrações sobre a configuração histórica das demandas do trabalho profissional.

A década de 1980 foi de extrema riqueza no debate teórico-metodológico, ético e político na ambiência profissional do Serviço Social, possibilitando a definição dos rumos profissionais nos seus aspectos técnicoacadêmicos e políticos. Um projeto profissional sólido e maduro foi pensado e constituído coletivamente no âmbito da categoria, com representações de todas as unidades do país, nas duas últimas décadas, 1980/90 sob a coordenação da Associação Brasileira de Ensino de Serviço Social (ABESS) e do Centro de Documentação e Pesquisa em Políticas Sociais e Serviço Social (CEDEPSS), com a participação do Conselho Federal de Serviço Social (CFESS), do Conselho Regional de Serviço Social (CRESS), e da Executiva Nacional dos Estudantes de Serviço Social (ENESSO). Como desdobramento desse projeto profissional, e sob a orientação de suas diretrizes, tem-se: o Código de Ética Profissional do Assistente Social, aprovado em 13 de março de 1993 com alterações introduzidas pelas Resoluções CFESS n. 290/94 e 33/96 (CRESS, 1996, p. 45); a Lei 8662/93, que regulamenta a profissão de Serviço Social; e a atual Proposta de Diretrizes Gerais para o Curso de Serviço Social, a qual está baseada no currículo mínimo aprovado em Assembleia Geral Extraordinária de 8 de novembro de 1996 (ABESS, 1996, p. 58-76; IAMAMOTO, 1998).

Não obstante, essa perspectiva de maturação política e intelectual dos assistentes sociais, bem como a construção do projeto profissional, não se processou sem maiores conturbações. Em pleno processo de construção do projeto ético-político (de consolidação ainda em curso), a categoria profissional teve que se afrontar com os impactos da flexibilização econômica e da política neoliberal, cujas estratégias resultaram: em precarização do trabalho; desemprego; intensificação do processo de desmontagem dos parcos direitos sociais e trabalhistas; dilapidação do patrimônio público, por meio das privatizações (inclusive das políticas e serviços sociais públicos); fragmentação da classe trabalhadora; e debilitação de suas formas de resistência e luta políticas.

As mesmas condições socioeconômicas e ideopolíticas que atingiram a classe trabalhadora reverberaram profundamente no Serviço Social. As mudanças históricas que alteraram a divisão social e técnica do trabalho na sociedade, corporificadas em mudanças nas relações Estado/sociedade e nas formas de organização e de gestão do trabalho, afetaram diferentes especializações, entre as quais o Serviço Social (IAMAMOTO, 1999). A reconfiguração do Estado, tal como foi conduzida nos anos 1990, acabou alimentando uma forte tendência de desresponsabilização pela política social, acompanhada do desprezo pelo padrão constitucional de seguridade social (BEHRING; BOSCHETTI, 2006). Mas isso não significou inexistência de política social, estas apenas foram adaptadas aos conflitos e demandas sociais ${ }^{1}$ engendrados no novo contexto de acumulação do capital.

As atuais condições de desenvolvimento do capitalismo, agudizadas pelo irracionalismo e o fundamentalismo, tornaram complexas as contradições e os desafios para a profissão de Serviço Social em várias dimensões, sobretudo na formação profissional, organização política, intervenção profissional e na produção de conhecimento. Não por acaso o aprofundamento da crítica que consolidou o projeto profissional, nos anos 1990, foi resultado de um processo de resistência teórico-política nos campos da formação e do exercício profissional.

\section{Princípios norteadores da proposta pedagógica da formação profissional em Serviço Social}

Nas Diretrizes Curriculares (PROJETO PEDAGÓGICO DO CURSO DE SERVIÇO SOCIAL DA UFRN, 1999) estão dispostos princípios gerais que norteiam as propostas pedagógicas de formação profissional no conjunto dos cursos de graduação na área do Serviço Social: flexibilidade de organização curricular, o qual permite ao discente maior liberdade na organização da sua vida acadêmica, uma vez que a proposta curricular não restringe o processo de ensino-aprendizagem apenas a atividades em sala de aula. Há diversificação de componentes curriculares expressos em seminários temáticos, oficinas, disciplinas optativas e atividades complementares como monitorias, extensão, participação em eventos científicos, estágios²; rigoroso trato teórico, histórico e metodológico da realidade social e do Serviço Social, a partir do qual a proposta pedagógica tem como perspectiva e pressuposto tratar a realidade social e o Serviço Social nela inserido com 
rigor teórico-histórico e metodológico, consciente que o assistente social deve estar habilitado a intervir de forma qualificada numa realidade social cada vez mais complexa; adoção de uma teoria social crítica que possibilite a apreensão da totalidade social em suas dimensões de universalidade, particularidade e singularidade, privilegiando a teoria social de Marx e marxista por entender que estas permitem melhor aproximação e desvendamento da realidade social enquanto totalidade.

Essa proposta pedagógica defende e propõe um estudo rigoroso e aprofundado de teorias que permitam conhecer e desvendar a realidade - especialmente a regional e local - em que se vai intervir, considerando as particularidades, as singularidades e estabelecendo necessárias mediações com a dimensão de universalidade por meio de uma intervenção qualificada, contrapondo-se ao mero localismo ou empiricismo. Trata-se, portanto, de formar profissionais aptos na apreensão das dimensões da particularidade e singularidade, atentos a realidade conjuntural e estrutural, prezando, no âmbito da formação acadêmica, pela indissociabilidade nas dimensões de ensino, pesquisa e extensão, e pelo estabelecimento das dimensões investigativas e interventiva como princípios formativos e condição central da formação profissional. A proposta pedagógica pautada pelas diretrizes estabelece a centralidade do perfil investigativo-interventivo do profissional de Serviço Social.

A aproximação e ou a inserção sistemática dos discentes nos espaços sócio-ocupacionais do trabalho profissional devem ser estimuladas e garantidas através do processo de estágio curricular, seja na modalidade obrigatória ou não-obrigatória, com vistas a viabilização de pequenas investigações, levantamentos e produção de dados sobre a realidade profissional como forma de apropriação e construção de conhecimento que deem suporte à intervenção profissional qualificada. É clara, na proposta de formação coordenada e defendida pela ABEPSS, a defesa do exercício do pluralismo como elemento próprio da vida acadêmica e profissional, permitindo aos alunos perceberem que a realidade social é um constante jogo de forças e de poderes entre diferentes projetos de sociedade, e que a formação profissional se desenvolve num contexto de lutas e embates entre projetos profissionais e sociais diversos. Ao mesmo tempo em que se recusa o monolitismo, a proposta pedagógica assume uma direção social e um projeto ético-político profissional, contudo entende que o projeto alimenta-se, necessariamente, da pluralidade e da diversidade sem perder sua unidade. A ética, como princípio formativo, perpassa toda a formação profissional em seus conteúdos curriculares e, na mesma medida, na relação professor-aluno, professor-professor, bem como em atividades de pesquisa e de intervenção, reforçando o compromisso na defesa dos direitos humanos, da democracia, da igualdade e da justiça social.

A formação profissional do assistente social se expressa em uma concepção de ensino-aprendizagem fundada na relação dinâmica entre Estado e sociedade, resultante de determinações macros societárias que estabelecem limites e possibilidades para a inserção profissional nos espaços sócio-ocupacionais das instituições. A formação profissional se propõe a "preparar cientificamente quadros profissionais capazes de responder às exigências de um projeto profissional coletivamente construído e historicamente situado" (IAMAMOTO, 1992, p. 163). A formação profissional não pode ser confundida com a simples preparação para o emprego. Ainda que não possa desconsiderá-lo, a formação profissional exige o necessário entendimento crítico da Universidade como instituição para formação profissional.

\section{Dimensão socioeducativa do estágio}

O saber transmitido na formação profissional integra conhecimentos teóricos, saberes interventivos, modelos, imagem ideal da profissão e valores que a legitimam e são acumulados no exercício profissional, no nível de suas consciências e do viver de formadores e formandos como atividade histórica e socialmente determinada pelas condições sociais. Os saberes da formação não são neutros, uniformes ou acabados, são uma construção histórica e, como tal, tributária de relações, tempos e espaços que a excedem. No Serviço Social, o distanciamento entre o saber e o fazer ${ }^{3}$ encontra-se mediado pelas condições sociais, históricas, econômicas e políticas que, ao longo do tempo, vêm espelhando polarizações e interesses na definição dos espaços do exercício profissional e em seu encaminhamento. Os conhecimentos não se fazem independentemente das condições concretas e históricas dos seus agentes profissionais, dos próprios sujeitos da formação e do jogo de interesses polarizados.

Não é apenas a informação teórica que forma o profissional. A formação atualiza, em seus objetos, a história e o contexto, a experiência e a vivência de indivíduos e de grupos. Logo, integra uma modelização da prática mediatizada pelo trabalho. É o trabalho, assim circunscrito ao exercício profissional e à própria experiência vivenciada pelo discente no campo de estágio em proximidade com o exercício profissional, que potencializa um conhecimento novo acerca de objetos do real, do concreto, filtrando-o em um movimento que o articula ao viver cotidiano da prática. Nessa mediação está o indivíduo ativo que, necessariamente, (re)constrói o que lhe chega ao se apropriar dos objetos e os objetiva em sua prática (PONTES, 2008). A experiência do exercício 
profissional, ao ser objetivado por um conjunto de atos que transformam ideias e finalidades previamente construídas na consciência em um produto objetivado, tem uma dimensão educativa ${ }^{4}$, uma das expressões da prática social, com particularidades e especificidades peculiares a esta profissão. Segundo Iamamoto (1986, p. 115), uma das características peculiares ao Serviço Social é constituir-se de "uma ação global de cunho socioeducativa ou socializadora, voltada para mudanças na maneira de ser, de sentir, de ver e agir dos indivíduos, que busca a adesão dos sujeitos"5. A dimensão educativa determina o caráter do exercício dessa atividade profissional construída e realizada por indivíduos que, ao se inserirem e atuarem numa determinada realidade, transformam-se através de sua própria ação (NICOLAU, 2015).

A dimensão socioeducativa é intrínseca ao trabalho na medida em que este, ao definir a inserção concreta do indivíduo numa totalidade social, possibilita-lhe, dialeticamente, a subjetivação, a objetivação e a historicização no contexto de relações sociais. Nessas relações, o indivíduo, objetivamente incorpora ao objeto de trabalho novos elementos, novas situações que antes não existiam. A dimensão socioeducativa, portanto, possibilita aos indivíduos o desenvolvimento de novos conhecimentos e de novas capacidades que passam a ser incorporados às novas pré-ideações em função de futuros atos de objetivação-exteriorização, enriquecidos, aprimorados e guiados por novos fundamentos na forma de conhecer, nas finalidades e nos meios utilizados no ato do trabalho. Tais elementos são decisivos para a apreensão dos nexos causais e das determinações mais importantes da realidade social, na qual o profissional atua e o discente vivencia sua experiência em um treinamento em serviço através do estágio. É nesse sentido que é demarcada a questão das competências e habilidades propostas nas Diretrizes Curriculares (1996), em que prevê a construção de uma competência teórica, ético-político e técnico-operativa.

É fundamental que as propostas curriculares preve-

\section{A massificação do ensino} superior e o aceleramento dos

processos formativos têm promovido uma

\section{desqualificação que se inicia no}

processo da formação e

desponta no seu produto social,

isto é, no perfil profissional

precário, incorporado ou

fartamente disponível para ser

absorvido pelo mercado de

trabalho. jam e definam a qualidade profissional do perfil do seu egresso, pois a garantia e a materialização dos princípios da formação se apresentam como um desafio constante na trajetória de cada etapa formativa. O estágio possui grande importância no processo de construção das competências profissionais. Em regra, é a partir dessa vivência que o discente-estagiário passa a ter clareza da necessidade de uma metodologia que oriente a análise e a intervenção profissional, possibilitando, a partir da totalização do fenômeno, a compreensão da realidade em movimento, partindo de sucessivas aproximações, operando uma lógica de pensamento que passa das categorias mais simples para as mais complexas, reconhecendo, no reconstruir histórico e concreto dos processos sociais, suas múltiplas determinações. O ofício da pesquisa é importante no e para o trabalho profissional implicando, pois, numa formação de profissionais com a capacidade de empreender uma leitura-análise situada no tempo e no espaço da realidade em movimento e da própria profissão nela inserida. Do mesmo modo a preocupação de implementar uma política de estágio que busque a articulação da graduação com a pós-graduação, além da articulação entre ensino, pesquisa e extensão, entendendo-os como níveis peculiares do processo de qualificação profissional do Serviço Social. E nesta perspectiva que se faz presente, também, o princípio da indissociabilidade nas dimensões de ensino, pesquisa e extensão.

O estágio não é o único momento em que o aluno se aproxima do fazer profissional, mas pode ser a realidade de currículos de muitas unidades brasileiras de formação acadêmica. A inserção do estudante em vivências pontuais em campo de estágio pode anteceder as vivências dos estágios obrigatórios propriamente ditos a partir de processos de aproximação sucessiva com a o exercício profissional, inclusive por meio de diversificados instrumentos de ensino oferecidos pelo curso, como atividades de campo, de pesquisa ou de trabalho em laboratório. Os cursos devem criar espaços e instâncias pedagógicas de debate acadêmico, de descoberta e de acompanhamento da realidade dos estágios a partir da área temática que envolve o estágio, ou de uma interlocução genérica que articule e abranja as diversas áreas de inserção profissional. Esse processo deve ser estimulado para fazer parte, em algum momento, das dinâmicas de trabalho dos Grupos de Pesquisa e articulados ao debate e às atividades da Pós-Graduação. O acúmulo do debate e a qualificação das experiências de estágio podem suscitar a concretização de atividades de extensão e pesquisa, podendo oferecer em 
sua programação os seminários temáticos, oficinas e tópicos especiais, em conformidade com a demanda. São nesses espaços que os alunos poderão problematizar as experiências de estágio e provocar o interesse em estudar temáticas de seu interesse e produzir seus trabalhos de conclusão de curso.

A forma de proceder no campo do estágio supervisionado exige dos professores, supervisores e discentes - protagonistas na efetivação do projeto pedagógico - um esforço coletivo e articulado na concretização das atividades e, ao mesmo tempo, uma contínua avaliação no processo de construção e de socialização do conhecimento produzido no processo de formação profissional, visando a competência teórica, metodológica, ética e política.

\section{Desafios da contracorrente}

Vivemos em tempos de profunda regressão social. As possibilidades históricas de construção de uma práxis universalmente emancipatória se mostram cada vez mais nebulosas e esgarçadas. Ditames da liberdade de mercado representam grandes ameaças à vida humana, impulsionando a tendência à homogeneização dos circuitos do capital, dos modos de dominação ideológica e dos objetos de consumo, apoiada na mais completa heterogeneidade e desigualdade social (IAMAMOTO, 2008). Nesse sentido, as determinações profissionais ${ }^{6}$ não passam incólume diante do contexto atual.

Mesmo hegemônico, o projeto ético-político profissional não é exclusivo. A tendência que essa conjuntura aponta é para a deflagração de tensões e disputas ainda maiores entre projetos e interesses no interior da categoria profissional. Por não estarem imunes aos processos sociais em curso, certamente expressarão influências e tendências advindas das camadas sociais e de seus conflitos, podendo expressar, inclusive, seu contrário. O rumo dos conflitos dependerá da defesa de uma vontade coletiva, da análise que os sujeitos profissionais façam da profissão e da sociedade, dos fundamentos, concepções, formas e dos métodos que utilizem na ação política.

O Serviço Social ocupa seu lugar na divisão sociotécnica do trabalho participando da tarefa de implementação de condições necessárias ao processo de reprodução social a partir, sobretudo, da inserção no campo das políticas sociais. Assistentes sociais são trabalhadores, vendem sua força de trabalho especializada para entidades empregadoras em troca de salário. Participam do processo de produção ou redistribuição da riqueza social, isto é, da criação do valor e da mais-valia (IAMAMOTO, 1998). Nesse sentido, a condição de assalariamento a qual os assistentes sociais estão submetidos é uma questão bastante relevante para ser considerada, tanto na análise sobre o pertencimento de classe na sua trajetória de construção política quanto na identificação dos seus principais e atuais desafios, que não se dissociam dos desafios de amplos setores da classe trabalhadora. Conforme o pensamento de Mota e Amaral (1998), os atuais desafios à profissão têm se desenvolvido em duas dimensões principais: a mais evidente e imediata relaciona-se com o exercício profissional, isto é, se expressam nas alterações do mercado de trabalho ${ }^{7}$ e nas condições do trabalho profissional. A outra dimensão é mais ampla e complexa, pois se refere ao surgimento de novas problemáticas que podem ser mobilizadoras de competências estratégicas, presentes na capacidade teórico-crítica e ético-política da categoria profissional.

Os atuais desafios profissionais do Serviço Social são as novas modalidades de produção e reprodução social da força de trabalho que, mediadas pelo mercado de trabalho profissional, passam a exigir a refuncionalização de procedimentos operacionais determinando um rearranjo de competências técnicas e políticas de acordo com o contexto da divisão social e técnica do trabalho. É importante compreender que as demandas sociais não se confundem com as necessidades sociais reais ${ }^{8}$ (MOTA; AMARAL, 1998).

Esse processo tem suscitado rebatimentos diretos e ofensivos na lógica do direito e na intervenção profissional dos assistentes sociais que atuam na área das políticas sociais. Sobretudo pela particularidade de serem profissionais que trabalham diretamente no planejamento, implementação e execução das políticas e serviços sociais que, em grande escala, são operacionalizados pelo Estado, ainda que também abranja empresas privadas, entidades filantrópicas e outras organizações. O desafio de identificar nas exigências e demandas profissionais "o conjunto das necessidades (políticas, sociais, materiais e culturais), quer do capital, quer do trabalho" (MOTA e AMARAL, 1998, p. 26), necessita ser enfrentado na elaboração de proposições teóricas, políticas, éticas e técnicas que se apresentem como respostas profissionais qualificadas para realização do projeto profissional do Serviço Social. Em meio a estas condições, outras expressões políticas da profissão, de variados tons neoconservadores, podem ganhar terreno e comprometerem a direção social da profissão. Nessa linha de raciocínio, Netto (2007, p. 38) afirma essas tendências mexem com os objetivos e funções profissionais. O elenco de objetivos do Serviço Social "tem intencional e acintosamente minimizado a centralização das suas funções no plano assistencial”" . Tal centralização teve início no período de implantação da política neoliberal nos anos 1990. Netto (2007) observa ainda que o fetiche dessa redução possui grande ressonância no interior da profissão, sobretudo na conjuntura política do "possibilismo prático" de um governo que se reivindica de esquerda ${ }^{10}$. 
Outra questão de fundamental importância na reflexão sobre essa conjuntura é a aceleração e a massificação desqualificante da formação profissional, sobretudo em virtude da expansão do ensino superior, especialmente da modalidade de educação a distância ${ }^{11}$. Para Braz (2007), essa problemática assinala duas tendências preocupantes relacionadas ao perfil profissional: uma aponta para a vulnerabilização da imagem da profissão e sua desvalorização na sociedade; a outra diz respeito ao desafio da formação de novos quadros teórico-políticos para o projeto profissional.

Quanto à questão da precarização da formação e do exercício profissional, a privatização e a precarização do ensino superior têm avançado a partir da pesada transferência de recursos públicos de financiamentos diretos, incentivos e isenções fiscais às empresas privadas na área de educação, em detrimento das universidades públicas. No entanto, no Brasil, em momento histórico algum esse projeto profissional esteve em plena sintonia com a direção dada à política educacional (RAMOS, 2009). Essas lutas continuam sendo encetadas na perspectiva de resistência e enfrentamento à inescrupulosa expansão do ensino superior. $\mathrm{O}$ acirramento dos conflitos e as disputas se explicitam com maior força no campo da formação, especialmente nas frentes em que estão em jogo: a consistência dos conteúdos relativos à formação teórico-metodológica; a concepção, a direção social e o fortalecimento da pesquisa e da produção de conhecimento na área; o ensino da prática, e nessa dimensão, a realização dos processos de estágio nas unidades de formação acadêmica. A massificação do ensino superior e o aceleramento dos processos formativos têm promovido uma desqualificação que se inicia no processo da formação e desponta no seu produto social, isto é, no perfil profissional precário, incorporado ou fartamente disponível para ser absorvido pelo mercado de trabalho.

Nessa última década, os processos de estágio - obrigatório ou não - dos cursos de graduação vêm chamando a atenção do conjunto das entidades representativas. A dimensão industrial, que orienta a produção de diplomas em nível superior, tem determinado uma espécie de abortamento daquelas etapas sócio-pedagógicas importantes e decisivas no processo da formação profissional. Têm sido frequentes as denúncias - no âmbito dos Conselhos Regionais de Serviço Social, em todo Brasil, e das regionais da ABEPSS - sobre fraudes e assédio moral contra profissionais da área de Serviço Social suscitadas pela disputa entre unidades de formação (em sua maioria privadas e de cursos na modalidade do ensino a distância) por espaços profissionais para a realização dos processos de estágio na área. Junto a isso há também outras questões adicionais, tais como: problemas relacionados à carga horária mínima em atividade de campo, que possui uma proporcionalidade percentual à carga horária total do curso de acordo com as Diretrizes Curriculares ${ }^{12}$; quantidade excessiva de aluno por supervisor de campo e de ensino ${ }^{13}$; qualidade e direção social empregada nesses processos de estágio, além de outras questões específicas e relativas a cada unidade de formação e região do país.

Ao longo desses últimos anos muitas iniciativas estratégicas foram pensadas pelas entidades organizativas e representativas em defesa da profissão e da formação profissional. Destacaremos aqui o Projeto ABEPSS Itinerante, realizado desde 2012. Nesse contexto adverso e na certeza das adversas implicações à consolidação das Diretrizes Curriculares, a ABEPSS, em 2012, propôs a estratégia do projeto com formato de curso de aperfeiçoamento, executado com grande êxito pela gestão 2011-2012, alcançando todas as regiões do Brasil e articulando diversas unidades de formação, públicas e privadas, filiadas e não filiadas à $\mathrm{ABEPSS}^{14}$. A versão do projeto do ano de 2014 trouxe para o debate a problematização dos processos de estágios na formação profissional - ABEPSS Itinerante 2014, Projeto ABEPSS Itinerante 2014, Estágio Supervisionado em Serviço Social: desfazendo os nós e construindo alternativas - tendo como principais objetivos: fortalecer a implementação da Política Nacional de Estágio (PNE) como estratégia para a ampliação da base político-acadêmica do plano de lutas em defesa do trabalho, da formação e contra a precarização do ensino superior nas unidades de formação acadêmica, considerando as particularidades de cada unidade de formação e em consonância com um projeto popular de universidade, democrática e socialmente referenciada; ampliação da política de formação continuada, tendo em vista o fortalecimento das estratégias nacionais e regionais da ABEPSS de enfrentamento à precarização do ensino superior; e contribuir com a interlocução permanente entre as instâncias da ABEPSS, o Conjunto CFESS/CRESS, ENESSO, as UFAS, os Assistentes Sociais Supervisores acadêmico e de campo (ABEPSS, 2014).

A implementação do projeto suscitou grandes debates em torno das problemáticas relativas ao estágio e garantiu melhores condições de avaliação, além de constatar as tendências deletérias no processo de formação, muitas vezes rebentadas no processo de realização do estágio. O conjunto dos desafios que se revelam nesses processos são de diversas e complexas ordens em razão de um contexto sócio-histórico densamente regressivo e contra-revolucionário. Quanto mais se acirram as condições para a defesa do projeto éticopolítico profissional, maior a necessidade de aprofundar a crítica e de construir a resistência que, por sua vez, somente pode se efetivar com muita coragem política, com capacidade de análise da realidade e com criatividade para composição de alianças estratégicas num campo social mais abrangente. 


\section{Em busca das conclusões}

As diretrizes, os princípios e os objetivos que a norteiam essa proposta pedagógica do estágio voltam-se para preparar os indivíduos para o mercado de trabalho, para pensar e contribuir na transformação da realidade na medida em que é possível ajudá-los a tematizarem as relações entre saber, fazer e poder, incorporando novos conhecimentos e novas habilidades. A grande particularidade desta proposta pedagógica reside na concepção de formação profissional que pode se objetivar na perspectiva de "preparar cientificamente quadros profissionais capazes de responder às exigências de um projeto profissional coletivamente construído e historicamente situado" (IAMAMOTO, 1992, p. 163).

A dimensão educativa, incluindo o estágio, é uma das expressões das especificidades da prática social do profissional do Serviço Social. Determina o caráter de uma atividade construída e realizada por indivíduos que se transformam por meio de sua própria ação. A dimensão educativa é um espaço contraditório que também possibilita ao assistente social, profissional e estagiário, construir e mediar a expressão de si mesmo como indivíduo social. Vale lembrar ainda que os limites do fazer profissional independem da vontade política dos sujeitos profissionais. São determinações que se apresentam nas relações de trabalho, nas condições institucionais do mercado de trabalho, bem como em dimensões sociais que perpassam e conformam a esfera da formação profissional. Por fim, esses limites alteram as condições nas quais se estabelecem os projetos de formação e a disputa pela sua materialização.

\section{Referências}

ABESS/CEDEPSS. Proposta básica para o projeto de formação profissional. Novos subsídios para o debate. Recife, set. 1996. ABESS. Proposta Básica para o Projeto de formação profissional. In: Revista Serviço Social e Sociedade, n. 50, ano XVII, abr. 1996.

ABESS. Diretrizes Curriculares e Pesquisa em Serviço Social. Caderno AABESS, n. 8, São Paulo, Cortez, nov. 1999.

BEHRING, E. R.; BOSCHETTI, I. Política social: fundamentos e história. São Paulo: Cortez, 2006.

BRASIL. Ministério da Educação. MEC. Resolução 02/2007 do Conselho Nacional de Educação. Brasília, 2007.

BRAZ, M. A hegemonia em xeque. Projeto ético-político do Serviço Social e seus elementos constitutivos. In: CFESS. Revista Inscrita n.10, Ano VII. Brasília, 2007.

CFESS. Lei de regulamentação da profissão de Serviço Social. Lei 8.662, de 7 de junho de 1993 - Dispõe sobre a profissão de Assistente Social e dá outras providências.

CFESS Resoluções 493/2006.

CFESS Resolução 533/2008.

CFESS, Conselho Federal de Serviço Social. Parâmetros para atuação de assistentes sociais na política de assistência social. Brasília, 2009.

GUERRA, Y. A formação profissional frente aos desafios da intervenção e das atuais configurações do ensino público, privado e à distância. Serviço Social \& Sociedade. n. 104. Ano XXX. São Paulo: Cortez. Novembro, 2010.

IAMAMOTO, M. V. Renovação e conservadorismo no Serviço Social. Ensaios Críticos. São Paulo, Cortez, 1992.

. O Serviço Social na contemporaneidade: trabalho e formação profissional. São Paulo: Cortez, 1998.

. O Serviço Social na contemporaneidade: trabalho e formação profissional. São Paulo: Cortez, 1999.

. Serviço Social em tempo de capital fetiche: capital financeiro, trabalho e questão social. São Paulo: Cortez, 2008.

MOTA, A. E.; AMARAL, A. S. do. Reestruturação do capital, fragmentação do trabalho e Serviço Social. In: MOTA, A. E. (Org.). A nova fábrica de consensos. São Paulo: Cortez, 1998.

MOTA. A. E. S da. (Org.). O Mito da Assistência Social: ensaio sobre Estado, política e sociedade. Recife. Ed. Universitária da UFPE, 2006. NETTO, J. P. Das ameaças à crise. In: CFESS. Revista Inscrita n. 10, Ano VII. Brasília, 2007.

NICOLAU, M. C. C. O aprender do fazer: Serviço Social, trabalho profissional e representações sociais. Natal: EDUFRN, Editora da UFRN, 2015.

. O estágio no processo da formação profissional de assistentes sociais e sua dimensão educativa. In: Silva. M. L. (Org.). Estágio Curricular: contribuições para redimensionamento de sua prática. UFRN, Natal, 2015.

PONTES, R. N. Mediação em Serviço Social. Um estudo preliminar sobre a categoria teórica e sua apropriação pelo Serviço Social. São Paulo: Cortez, 2008.

PROJETO PEDAGÓGICO DO CURSO DE SERVIÇO SOCIAL DA UFRN. Curso de Serviço Social da UFRN, Natal, 1999. RAMOS, S. R. Limites e Possibilidades Históricos do Projeto Ético-Politico. In: CEFESS. Revista Inscrita n. 12, ano IX Brasília, 2009. 


\section{Notas}

1 No contexto de reestruturação produtiva - cujo significado para a classe trabalhadora se traduziu em aumento do desemprego e dos níveis de pobreza - houve crescente demanda social por políticas sociais públicas, o que consistiu numa grotesca contradição diante do desmonte do Estado de direito. Seria impossível elencar aqui as demandas do capital para o Estado, mas vale ressaltar que a contrarreforma consistiu em exigência do próprio capital, como forma de intensificação da exploração do trabalho e da expropriação social.

2 Oestágio deve ser inserido nos currículos "como uma atividade curricular obrigatória que se configura a partir da inserção do aluno no espaço sócio institucional objetivando capacita-lo para o exercício profissional, o que pressupõe supervisão sistemática" (ABESS, 1999).

3 A separação entre teoria e prática encontra-se subjacente à racionalidade hegemônica do capitalismo, repõe sua alienação essencial - separação entre os proprietários e não proprietários dos meios de produção-de modo que a cisão entre os que pensam e os que executam - que fundamenta a alienação no trabalho - é particularizada na ordem burguesa constituída como o processo de reificação. Produto necessário do processo de reificação é uma concepção de conhecimento que não ultrapasse a aparência dos fatos; que não supere o âmbito da experiência imediata; que conceba os fenômenos na sua positividade; que descarte o seu movimento de constituição e que, por isso, não seja capaz de captar o movimento; que suprima as mediações sociais constitutivas e constituintes dos processos. Sem o conhecimento dos fundamentos, a elaboração teórica negase a si mesma (GUERRA, 2010).

4 Essa dimensão educativa se faz presente nos documentos da representação política da categoria: CFESS (2012); Parâmetros para Atuação de Assistentes Sociais na Política de Assistência Social (2009); Parâmetros para Atuação de Assistentes na Politica de Sociais na Saúde (2009); e Parâmetros paraAtuação de assistentes Sociais na área Sociojurídica (2014). Nestes documentos, a dimensão educativa aparece como pedagógicointerpretativa dentre as seis dimensões interventivas do Serviço Social.

5 As particularidades e especificidades da dimensão educativa do fazer-profissional do assistente social circunscrevem espaços social e simbólico próprios, portanto não se confunde nem substitui a que cabe à escola, lugar privilegiado da transmissão do "saber sistematizado", do "conhecimento elaborado" e da "cultura erudita" (SAVIANI, 1991, p. 22).

6 É preciso análise crítica e convicção ético-política para não se ater apenas às características e demandas do mercado de trabalho profissional, postas, atualmente, pela reestruturação produtiva e pela desestruturação do Estado de direito, e não esquecer que as demandas sociais são mera aparência, não expressam as necessidades sociais da classe trabalhadora, inclusive as transfiguram em seu contrário (MOTA;AMARAL, 1998).

7 As características do mercado de trabalho podem oferecer um conjunto de informações a partir das quais é possível identificar as necessidades sociais que estão subjacentes às demandas profissionais. Istoé, constitui-se um espaço eminentemente contraditório no qual, também, se revelam os interesses conflitantes de classes antagônicas (MOTA; AMARAL, 1998).

8 As demandas sociais, a rigor, são requisições técnico-operativas que, através do mercado de trabalho, incorporam as exigências dos sujeitos demandantes. Em outros termos, elas comportam uma verdadeira teleologia dos requisitantes a respeito das modalidades de atendimento de suas necessidades. Por isso mesmo, a identificação das demandas não encerra o desvelamento das reais necessidades que as determinam (MOTA; AMARAL, 1998).

9 Mesmo encontrando esteio em determinados vetores profissionais, essa tendência não tem sido fortalecida como perspectiva única no debate interno da profissão. O pensamento crítico do Serviço Social vem desenvolvendo análises de profunda consistência teórica acerca das políticas sociais na realidade brasileira. Dentre as discussões mais recentes e polêmicas, destacam-se: Mota (2006); Behring (2006) e Boschetti (2006).

10 Referência aos governos chefiados pelo Partido dos Trabalhadores (PT).

11 Houve grande embate político com o Ministério da Educação (MEC) para tentar frear a abertura de cursos de graduação a distância na área de Serviço Social, sobretudo com a intenção de dialogar criticamente com a sociedade sobre os fundamentos desse modelo de formação. ACampanha Nacional "Educação nãoé fast food ", lançada pelas entidades nacionais representativas da profissão, (CFESS/CRESS, ABEPSS eENESSO), foi suspensa por força judicial.

12 A resolução n. 02/2007 do Conselho Nacional de Educação estabelece o percentual em até 20\% da carga horária total mínima dos cursos de bacharelado na modalidade presencial. A carga horária total mínima estabelecida para o curso de Serviço Social é de três mil horas.

13 Mecanismos políticos, pedagógicos e legais foram criados na perspectiva de uma parcial autonomia profissional, tendo em vista a defesa da formação e do exercício profissional, que incidiram na regulamentação do processo de realização do estágio supervisionado na área. Com base nas diretrizes curriculares, na lei que regulamenta a profissão e no Código de ética Profissional, foram construídas a Política Nacional de Estágio (PNE) e as Resoluções 493/2006 e 533/2008 do CFESS.

14 De acordo com a ABEPSS/Nacional, em sua primeira versão, o projeto alcançou todas as regiões brasileiras, contemplando cerca de 400 participantes, os quais se comprometeram, em sua maioria, com a socialização e multiplicação da proposta nos diversos espaços da formação profissional, do estágio supervisionado, da atuação institucional e das comissões dos CRESS. Visava também o compromisso em contemplar os conteúdos e os questionamentos apreendidos/desenvolvidos em projetos de pesquisas e de extensões no interior de suas Unidades de Formação Acadêmica (UFAs).

\section{Maria Celia Correia Nicolau}

mccnicolau@gmail.com

Doutora em Educação pela Universidade Federal do Rio Grande do Norte/UFRN

Professora do Departamento de Serviço Social da Universidade Federal do Rio Grande do Norte (UFRN) 


\section{Tassia Rejane Monte Santos}

tassia.s.social@ hotmail.com

Mestrado em Serviço Social pela Universidade Federal do Rio Grande do Norte

Professora do Departamento de Serviço Social da Universidade Federal do Rio Grande do Norte (UFRN)

\section{UFRN}

Rua: BR 101 s/n Bairro Lagoa Nova

Centro de Ciências Sociais, Departamento de Serviço Social (DESSO)

Natal - Rio Grande do Norte - Brasil

CEP: 59072-970 